\title{
Correction to: Do women directors contribute to R\&D? The role of critical mass and expert power
}

\author{
Sara Saggese $^{1} \cdot$ Fabrizia Sarto $^{1} \cdot$ Riccardo Viganò $^{1}$ \\ Published online: 4 July 2020 \\ ๑) Springer Science+Business Media, LLC, part of Springer Nature 2020
}

\section{Correction to: Journal of Management and Governance (2020) https://doi.org/10.1007/s10997-020-09513-1}

Figure 1 has been published incorrectly in the original publication of the article. The correct version of the figure is provided with this correction.

The original article can be found online at https://doi.org/10.1007/s10997-020-09513-1.

\section{Sara Saggese}

sara.saggese@unina.it

Fabrizia Sarto

fabrizia.sarto@unina.it

Riccardo Viganò

riccardo.vigano@unina.it

1 Department of Economics, Management, Institutions, University of Naples "Federico II", Via Cinthia, Monte S. Angelo, 80126 Naples, Italy 


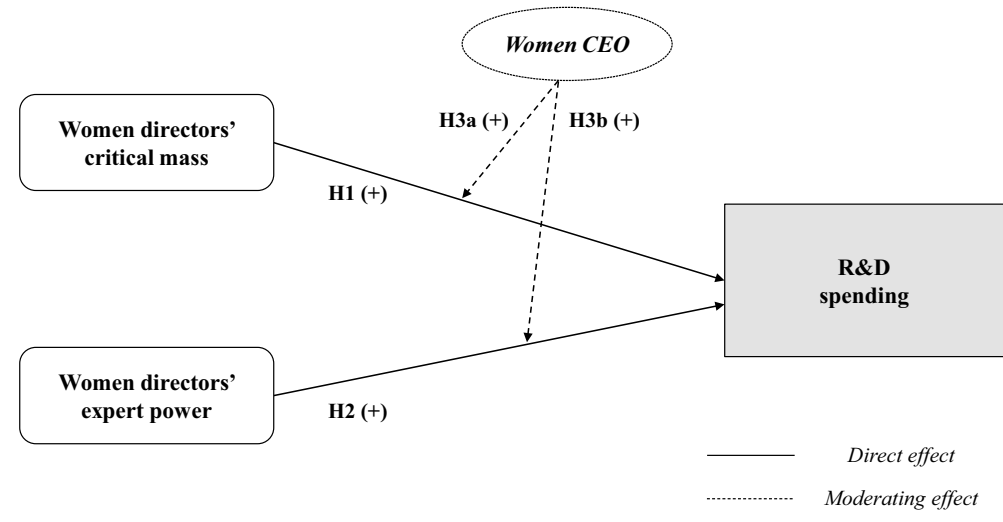

Fig. 1 Research hypotheses

The original article has been corrected.

Publisher's Note Springer Nature remains neutral with regard to jurisdictional claims in published maps and institutional affiliations. 